\title{
Sex differences in learning the allocation of social grooming in infant stumptailed macaques
}

\author{
Ricardo Mondragón-Ceballos ${ }^{1,3)}$, Pilar Chiappa ${ }^{1)}$, \\ Lilian Mayagoitia $^{1)}$ \& Phyllis Lee ${ }^{2)}$ \\ ( ${ }^{1}$ Instituto Nacional de Psiquiatría Ramón de la Fuente, Ethology Department, Calzada \\ México-Xochimilco 101, Col. San Lorenzo Huipulco, Tlalpan 14370, Mexico City, Mexico; \\ ${ }^{2}$ Behaviour and Evolution Research Group, Department of Psychology, University of \\ Stirling, Stirling, UK)
}

(Accepted: 15 April 2010)

\begin{abstract}
Summary
Among primates, the intense mother-infant bond provides offspring with a lengthy period for learning from an experienced and reliable demonstrator. Since adult life differs for females and males, the expertise of mother may not be equally useful to both sexes of infant, particularly with regard to social relationships. Here, we report on differences between infant female and male stumptailed macaques in learning how to allocate social grooming, using their mothers as demonstrators. Infant females were significantly more socially precocious than males, starting at early ages to groom mothers. Throughout their first year of life, daughters showed more instances of mirroring mothers' behaviour than sons did. In addition, while grooming on their own, grooming durations of daughters to specific partners was significantly concordant with time devoted by mothers to such recipients. We suggest that daughters learn from their mothers how to distribute grooming amongst social companions, while sons primarily use mother as a secure platform to initiate socializing. These results lend support to the idea that mirroring equates with learning and leads to reinforcement of innate propensities for gender roles in primates.
\end{abstract}

Keywords: social learning, allogrooming, sexual differences, mother-offspring, stumptailed macaques, intergenerational transmission.

\footnotetext{
3) Corresponding author's e-mail address: rmc@imp.edu.mx 


\section{Introduction}

In vertebrates relying on maternal expertise to acquire or reinforce behaviour through social learning is purportedly an adaptive mechanism that ensures survival and enhances fitness by preventing immature subjects from engaging in behaviour that, if attempted by individual trial-error learning, might be deadly or injurious (Galef, 1996; but see Laland, 1996). Keverne et al. (1996) and Broad et al. (2006) have proposed that the mammalian brain evolved to favour mother-offspring attachment (sensu Bowlby, 1969, 1973). In primates, learning to make decisions via maternal examples may account for the enlargement of the neocortex (Keverne et al., 1996); a conclusion also reached by Joffe (1997) with regards to the primate extended juvenile period.

Primate mothers are recognized as a main referential model for a diversity of socially learned or reinforced behaviours (Altmann, 1980; Horvat \& Kraemer, 1981; Wallen et al., 1981; Fairbanks \& McGuire, 1986; Fairbanks, 1989; Berman, 1990, 2004; McGrew, 1992; Tanaka, 1995; Huffman, 1996; de Waal, 1996; Berman et al., 1997; Tanaka, 1998; Berman \& Kapsalis, 1999; Drapier \& Thierry, 2002; Maestripieri, 2003; Weaver \& de Waal, 2003; Lonsdorf et al., 2004; Schino et al., 2004; Weaver et al., 2004; Lonsdorf, 2005, 2006; Suomi, 2005; Maestripieri et al., 2007). Mother-offspring attachment including close proximity provide the confidence and visual opportunities to use mother as a model, even if this might perpetuate behaviour of low efficiency (Tanaka, 1995, 1998; Drapier \& Thierry, 2002) or abusive mothering styles prone to reduce fitness (Fairbanks, 1989; Berman, 1990; Maestripieri, 2003; Maestripieri et al., 2007). As infants age, they are able to modify behaviour learned from mothers by using other models such as peers (Wallen et al., 1981; Berman, 1982; Ehardt \& Bernstein, 1987; Lee \& Johnson, 1992; Huffman, 1996; de Waal, 1996; Suomi, 2005; Leca et al., 2007) or by independent learning (Berman \& Kapsalis, 1999). Thus, upon reaching adulthood daughters need not necessarily replicate their mothers' behaviour (Schino et al., 2004).

Despite Altmann's (1980) suggestion that female baboons (and thereby other primate species) may be specially primed to learn social relationships from mothers' behaviour, few studies directly address whether or how offspring sex interacts with the use of mother as a referential model (Rapoport, 1985; McGrew, 1992; Bernstein et al., 1993; Deputte \& Quris, 1996; Lonsdorf et al., 2004; Lonsdorf, 2005, 2006). Most of the prior work focuses 
on daughters or analyzes and reports sex differences as an intervening variable, rather than being included in hypotheses, even though sex differences in learning abilities during development exist (Bachevalier \& Hagger, 1991; Hagger \& Bachevalier, 1991).

Sex differences in social development foreshadow immature sex-specific adult life histories (Pereira \& Altmann, 1985; Walters, 1987; HiraiwaHasegawa, 1997; Cords, 2000). Primates, like most vertebrates (Morris et al., 2004), are born with a sexually differentiated brain, one proximate mechanism underlying behavioural sex differences (Wallen, 2005). Being born with this sexually differentiated brain allows for learning and the practice of relevant adult behaviour long before facing the demands of reproductive and adult social life. Thus, prenatal differentiation of the brain might fall among what Setchell \& Lee (2004) identify as sex-specific developmental pathways arising from age-dependent selection pressures linked to distinct adult reproductive strategies, constrained by time and energy expenditure for both mothers and the developing immatures.

Studies of sex-specific reliance on the maternal expertise necessary to acquire adult competence suggest that differences exist and that these are related to the type of behaviour being learned (McGrew, 1992; Lonsdorf et al., 2004; Agostini \& Visalberghi, 2005; Lonsdorf, 2005, 2006; Leca et al., 2007). Since the pioneering study of Sade (1965), immature female rhesus macaques are known to develop social networks similar to those of their mothers (Suomi, 2005). Subsequent studies of kin-biased intergenerational transmission have been mainly female-centred (de Waal, 1996; Schino et al., 2004; capuchins: Perry et al., 2008). While Berman \& Kapsalis (1999) found no sex differences in kin biased spacing behaviour in infant and juvenile rhesus monkeys, Cords (2000) found that immature female blue monkeys develop similar allogrooming preferences to those of their mothers, although their sons do not. Berman \& Kapsalis (1999) acknowledge that little is still known about the processes involved in developing and perpetuating kin biased (or other social) networks. In addition, development is a period of intense learning across a range of modalities including maternal examples (Berman et al., 1997). All in all, networks or social preferences of yearlings resemble those of their mothers, but this effect is not always seen at later ages. If social risk during infancy influences social learning, then this risk will determine whether or not such resemblance will endure until adulthood. 
Our study addresses whether (1) infant stumptailed macaques, Macaca arctoides, use mothers as the main model to learn allogrooming (henceforth grooming) preferences (i.e., how much or how often to groom each group member) and (2) if females and males differ in the extent to which they rely on maternal expertise. If infants are able to learn the allocation of grooming from their mother, we predict that they will mirror maternal behaviour (sensu Berman, 2004) to a greater extent than compared to another female that simply keeps close proximity to her mother (i.e., mother's best friend, sensu Silk, 2002). Thus, we expect that infants will show more instances of grooming together and devoting proportionally more time to grooming alongside mothers than with mothers' best friend (prediction 1). Moreover, if mothers are the main social models, we expected that whenever infants groom on their own, they will groom more often and/or for longer times the preferred partners of mothers (prediction 2). In turn, grooming allocation by infants should match the social biases of mothers, such as being kin-biased, rank-biased or showing the same idiosyncratic grooming preferences (prediction 3).

If, as we discuss above, daughters are more disposed than sons to learn from their mothers, the daughters should also be more socially precocious. For instance, daughters should begin to engage in grooming interactions at younger ages (prediction 4). Additionally, daughters should display higher rates of social mirroring (prediction 5) and more concordance with maternal behaviour than will sons (prediction 6). Finally, daughters' social biases would be more akin to those of mothers (prediction 7).

\section{Method}

\section{Subjects}

We studied 26 captive stumptailed macaques, 14 females and 12 males, from birth until 2 years old. These animals were born at the facilities of the Instituto Nacional de Psiquiatría in Mexico City between 1981 and 1998, to 10 different mothers (Table 1). The stumptailed macaque colony was formed in 1973-1974, and consistently ranged from 27 to 33 animals across all age-sex categories (newborns to adults). Until 1996, animals were kept in three different outdoor groups (each cage $49 \mathrm{~m}^{2}$ floor area plus $12 \mathrm{~m}^{2}$ of cornices). 
Table 1. Demographic characteristics of the sample.

\begin{tabular}{|c|c|c|c|c|c|c|}
\hline Infant & Mother & $\begin{array}{c}\text { Sex } \\
\text { of infant }\end{array}$ & Birth of infant & Parity ${ }^{\mathrm{c}}$ & $\begin{array}{c}\text { Focal } \\
\text { samplings (h) }\end{array}$ & $\begin{array}{c}\text { Rank of mother at } \\
\text { birth of infant }\end{array}$ \\
\hline $\mathrm{MG}^{\mathrm{a}}$ & $\mathrm{CA}$ & q & May 6, 1981 & 2 & 84 & Dominant \\
\hline $\mathrm{LA}^{\mathrm{a}}$ & $\mathrm{CH}$ & 우 & Sep. 6, 1982 & 2 & 92 & Subordinate \\
\hline $\mathrm{VI}^{\mathrm{a}}$ & $\mathrm{CN}$ & $0^{x}$ & Sep. 13,1982 & 6 & 92 & Dominant \\
\hline LI & $\mathrm{CN}$ & 우 & Aug. 7, 1984 & 7 & 136 & Dominant \\
\hline $\mathrm{TA}$ & $\mathrm{CA}$ & $0^{x}$ & Aug. 15, 1984 & 4 & 136 & Dominant \\
\hline IS & MA & 우 & Jun. 14, 1985 & 1 & 32 & Intermediate \\
\hline SA & $\mathrm{CA}$ & $0^{x}$ & Apr. 23, 1986 & 5 & 30 & Dominant \\
\hline $\mathrm{NU}$ & $\mathrm{CN}$ & ㅇ & Jul. 18, 1986 & 8 & 32 & Dominant \\
\hline FR & GR & $0^{x}$ & Dec. 4, 1986 & 4 & 31 & Dominant \\
\hline JA & $\mathrm{CA}$ & 우 & Jul. 2, 1987 & 6 & 32 & Dominant \\
\hline $\mathrm{CU}$ & $\mathrm{TI}$ & $q^{+}$ & Sep. 25,1987 & 4 & 32 & Intermediate \\
\hline $\mathrm{PO}$ & $\mathrm{CN}$ & $0^{x}$ & Sep. 25,1987 & 9 & 29 & Dominant \\
\hline DW & MA & $0^{x}$ & Dec. 4,1987 & 2 & 31 & Intermediate \\
\hline $\mathrm{AU}$ & $\mathrm{CA}$ & q & Feb. 27, 1989 & 7 & 32 & Dominant \\
\hline $\mathrm{AL}$ & $\mathrm{CA}$ & $0^{x}$ & May 3, 1990 & 8 & 32 & Dominant \\
\hline ES & TI & $0^{x}$ & May 23, 1990 & 5 & 32 & Intermediate \\
\hline SX & $\mathrm{CA}$ & $0^{7}$ & Nov. 15,1991 & 9 & 28 & Intermediate \\
\hline $\mathrm{R} 1$ & $\mathrm{NU}$ & 우 & May 30, 1992 & 1 & 28 & Intermediate \\
\hline $\mathrm{R} 2^{\mathrm{b}}$ & $\mathrm{TI}$ & 우 & Dec. 1, 1992 & 7 & 32 & Dominant \\
\hline JR & $\mathrm{AU}$ & $0^{x}$ & Feb. 20, 1994 & 1 & 28 & Intermediate \\
\hline GA & $\mathrm{TI}$ & $0^{x}$ & May 8, 1994 & 8 & 28 & Dominant \\
\hline $\mathrm{MN}$ & $\mathrm{AU}$ & q & May 29, 1997 & 2 & 32 & Intermediate \\
\hline $\mathrm{SO}$ & MA & 우 & Jan. 8, 1998 & 3 & 32 & Subordinate \\
\hline SE & $\mathrm{AU}$ & $0^{x}$ & Jun. 2, 1998 & 3 & 30 & Dominant \\
\hline $\mathrm{LU}$ & JA & 우 & Jun. 8, 1998 & 3 & 32 & Intermediate \\
\hline $\mathrm{LZ}$ & $\mathrm{R} 1$ & 우 & Nov. 27, 1998 & 2 & 30 & Subordinate \\
\hline
\end{tabular}

${ }^{\text {a }}$ Data from birth were not available.

${ }^{\mathrm{b}}$ Subject died being 11 months old.

${ }^{\mathrm{c}}$ Birth number including stillborns.

From April 1996, they were merged into a single group housed in a large outdoor cage ( $148 \mathrm{~m}^{2}$ floor area plus $36 \mathrm{~m}^{2}$ of cornices). This provided a more challenging and variable social environment for the macaques. Details on diet, feeding regime and water availability are found in Mondragón-Ceballos (2001).

We also collected data from 10 mothers and 10 additional females as controls (control female models). The control females were the 'best friends' of mothers; chosen as the female with whom the mother exchanged (gave and 
received) more than $10 \%$ of her total social grooming time (Dunbar, 1983) in the month prior to the birth of the infant being sampled. Whenever a mother had more than one friend, we chose as control female that with the highest percentage of grooming exchanged even if the difference with the next closest one was around or less that $1 \%$. Friendships between female stumptailed macaques are usually life-long and actively maintained, irrespectively of the number of juvenile and adult daughters present (personal observations). Consequently, there were no changes in friendships throughout the study, control females being as constant as mothers were.

In six cases, control females were unrelated to mothers; control females were putative half-sisters of mothers in two cases (born to different, unrelated mothers during the tenure of a same alpha male) while in the remaining two a matriarch and her eldest daughter were control females of each other. The inclusion of related females as controls did not introduce any meaningful bias in analyses. Data collection for infants, mothers and control females was done simultaneously.

We calculated social ranks for every 6-month period using Boyd \& Silk's (1983) method for assigning cardinal ranks, based on composite sociomatrices of dyadic agonism given (aggressions and threats) + submissions received. To assign the categorical ranks shown in Table 1, we classified as dominants those females occupying the upper-third positions within the female rank ordering. Intermediates are those in the middle-third positions, and subordinate the females occupying the bottom-third positions. Up to 1.5 years old, we assigned immature stumptailed macaques the same cardinal rank as their mothers; thereafter we incorporated immatures into cardinal rank calculations. In all instances, regardless of their sex, they ranked closely, although not always adjacent, below their mothers.

\section{Behaviour sampling}

Data come from ad libitum, focal and instantaneous sampling (Altmann, 1974). Before July 1985, we collected data by daily ad libitum and 1-h focal observations on 6 animals. From July 1985 to December 2001, we collected data on focal animals using video-recording and instantaneous sampling. From July to December 1985, 11 animals were each sampled daily for one hour (between 0800 and 1900 h); from January 1986 onwards focal samples lasted $10 \mathrm{~min}$. All 10-min focal samples were collected by daily recording 
(Mondays-Fridays) from 9 randomly chosen animals at randomly selected times between 0800 and $1900 \mathrm{~h}$. This procedure ensured collecting at least two focal samples per animal each week. On two occasions (September 1992 and 1994) three weeks elapsed between successive samples. We took instantaneous scan samples every half-hour from 0700 to $1900 \mathrm{~h}$. In each scan, we recorded activities, interactions, proximity and neighbours from all animals in the colony. Again, besides from the periods mentioned above, gaps in instantaneous scan samples were never longer than 1-2 days, and never skipping more than two consecutive sampling periods within a single day.

\section{Behaviour studied}

We define 'grooming' as picking through, separating or combing the hair of another animal using fingers or mouth. A grooming bout was defined as any interaction lasting more than $5 \mathrm{~s}$, as shorter interactions are used to request grooming (personal observations). We considered that a grooming bout ended whenever one or both animals involved departed, if actors exchanged roles, or if the interaction was interrupted for more than $20 \mathrm{~s}$ before being resumed. Simultaneous mutual grooming (where 2 animals participated together as givers) was considered as a single interaction, but duration of each groomer was recorded separately. We analysed only interactions where offspring, mothers and control females were the givers, but not the recipients, of grooming ( $N=33059)$. In comparisons of how similar infant grooming was to that of mothers and control females, we divided data into four 6-month age-categories (birth- 6 months old; $>6$ months -1 year; $>1$ year -1.5 years; and $>1.5-2$ years old) and used the following indices.

\section{Mirroring}

We used 2 behaviours as measures of mirroring mothers and control females (adult females models) grooming behaviour (predictions 1 and 5). (1) The percentage of instances per immature age-category that the adult female model and an immature were recorded simultaneously grooming the same animal. (2) The percentage of time that infants groomed alongside adult female models relative to the total grooming duration ((infant duration/entire grooming session duration) $\times 100$ ) . 
Duration agreement

Duration (in s) of grooming given by an immature to a specific recipient who had also been groomed by the adult female model within the past hour of accumulated focal samples. Unlike mirroring, the infants did not groom together with their adult female models, but groomed on their own (predictions 2 and 6), even though (mainly in the first age-category) mothers could be nearby.

\section{Frequency agreement}

Number of grooming bouts given by an immature to a specific recipient who had also been groomed by the adult female model within the past hour of accumulated focal samples. As in duration agreement, grooming was not performed simultaneously with adult females. We considered time and frequency agreement as instances of independently rehearsing learning from adult females (predictions 2 and 6).

\section{Social biases}

We used 3 measures of social bias: kin bias, rank bias and idiosyncratic preferences (de Waal, 1996; Schino, 2001; Schino et al., 2004). Bias measures were obtained by regressing the percentage of time allocated to grooming each group member per 6-month period on kin coefficients and cardinal ranks. From these regressions, we determined the unstandardised residuals for kin, rank and remaining individuals so as to assess bias. We performed 2 such multiple regressions, one for infants and the other for adult females. Multiple regressions were done over the entire infant and adult female samples, without distinguishing infants' sex, age or adult female relatedness, so as to ensure that residuals contained variance due to sex, age and relatedness, which could then be explored. Analysing the P-P, Q-Q and residuals vs. independent variables plots confirmed that residuals were not normally distributed and were highly dispersed (when plotted against independent variables). We considered kin coefficients exclusively from the maternal line obtained from genealogical records, as described in López-Vergara et al. (1989). Kin and rank biases and idiosyncratic preferences were used to assess the similarity between infants' networks with those of mothers and control females (predictions 3 and 7). 
Analyses

We used the Generalized Linear Mixed Model (GLMM) (McCulloch \& Searle, 2001) to assess the effects of sex of infant, adult female model (mother or control female) and age-category on mirroring. We choose GLMM to control for repeated sampling of the same subjects (infants, mothers and control females) and gaps in the sample. Covariance structure of within-subjects effects was modelled as a first-order autoregressive series $(\mathrm{AR}(1))$. We employed the sequential Bonferroni procedure in post-hoc contrasts of significant age effects and interactions.

We performed a series of cross-sectional analyses to assess agreement of grooming frequency and duration between infants and adult female models at the ages-categories above defined. Assessment of grooming frequency and grooming duration matching was done by means of weighted Linear Regressions to control for repeated sampling of subjects. We assigned weights using the clustering procedure described in Manson et al. (2004). Clusters were calculated as the number of times per age category infants and adult female models groomed the same animal, with weights being the inverse of the cluster (e.g., 1/(mother A grooming instances to $\mathrm{C}+$ daughter $\mathrm{B}$ grooming instances to $\mathrm{C}$ )). Immature stumptailed macaques that accounted for less than three matching instances per 6-month period were dropped from analyses. As none of our dependent variables were normally distributed, besides from being heteroscedastic, arcsine transformed percentages, logarithmic transformed durations, and square root transformed frequencies were used in GLMM and Linear Regressions analyses.

Finally, we did a series of cross-sectional Generalised Linear Mixed Model Regressions (GLMRs) to estimate matching of infants'-adult female models' kin bias, rank bias and idiosyncratic preferences at different ages. We used van de Pol \& Wright (2009) within-subject centring procedure, equations (2) and (3), to distinguish and estimate within- and betweensubjects effects, and to assess within- versus between-subjects slope differences. We regressed infants' kin bias, rank bias and unstandardised residuals on within-subject centred mothers' or control females' kin bias, rank bias and unstandardised residuals, respectively. Entering infants, adult females and grooming recipients' identifications into the GLMR was a further control of multilevel aggregation effects. The $\mathrm{R}$ 2.5.1 package (Venables et al., 2007) was used to perform all analyses and G*Power 3.1 (Faul et al., 
2007) was used to perform sensitivity and achieved power tests. All tests are two-tailed and the significance level was set at $\alpha \leqslant 0.05$. For multiple paired contrasts, in addition to the sequential Bonferroni procedure restrictions, we set $1-\beta \geqslant 0.84$ for a mean difference to be considered significant.

\section{Results}

Age at first grooming

Data from 19 infants (females $=9$, males $=10$ ) provided reliable information about the age at which grooming commenced. The first animal groomed by infants was the mother, except for one male whose first grooming was to the group's alpha male. Females tended to start to groom their mother at a younger age than did males (females: mean $\pm \mathrm{SE}=74.5 \pm 9$ days of age; males: $102.4 \pm 11.4$ days of age; Mann-Whitney $U=21.5, N_{1}=10$, $N_{2}=9, p=0.052$ ). Similarly, females started grooming other animals at a significant younger age (females: $83 \pm 10.7$ days; males: $130.2 \pm 13$ days; $U=15.5, p=0.01)$. Throughout their infancy, females engaged in more grooming interactions than did males (females: $15.8 \pm 1.6$ bouts/h, males: $11.5 \pm 1.6$; GLMM: $N=3207, F_{1,18.3}=5.268, p=0.034,1-\beta=0.78$ ) and as infants aged, grooming duration increased significantly for both sexes $\left(F_{3,204.1}=3.212, p=0.024,1-\beta=0.87\right)$.

\section{Percentage of instances and proportion of time of grooming together with an adult female}

The percentage of instances where offspring and mothers simultaneously groomed the same recipient varied significantly between sexes (GLMM: $\left.N=208, F_{1,19.5}=15.945, p=0.001,1-\beta=0.93\right)$ and by age $\left(F_{3,69.8}=8.019, p<0.001,1-\beta=0.99\right)$, with an interaction between sex and age $\left(F_{3,69.8}=9.179, p<0.001,1-\beta=0.95\right)$. The same trends were found for all grooming involving adult female models (sex $\times$ adult female model: $F_{1,34.9}=14.383, p=0.001,1-\beta=0.94$; age $\times$ adult female model: $F_{3,80.2}=3.275, p=0.025,1-\beta=0.63$; sex $\times$ age $\times$ adult female model: $F_{3,80.5}=2.746, p=0.048,1-\beta=0.48$; see Figure 1). Throughout the first and half year of life the percentage of instances daughters groomed alongside mothers was significantly higher that of sons (Figure 1a); daughters were also in company of control females more than sons until 


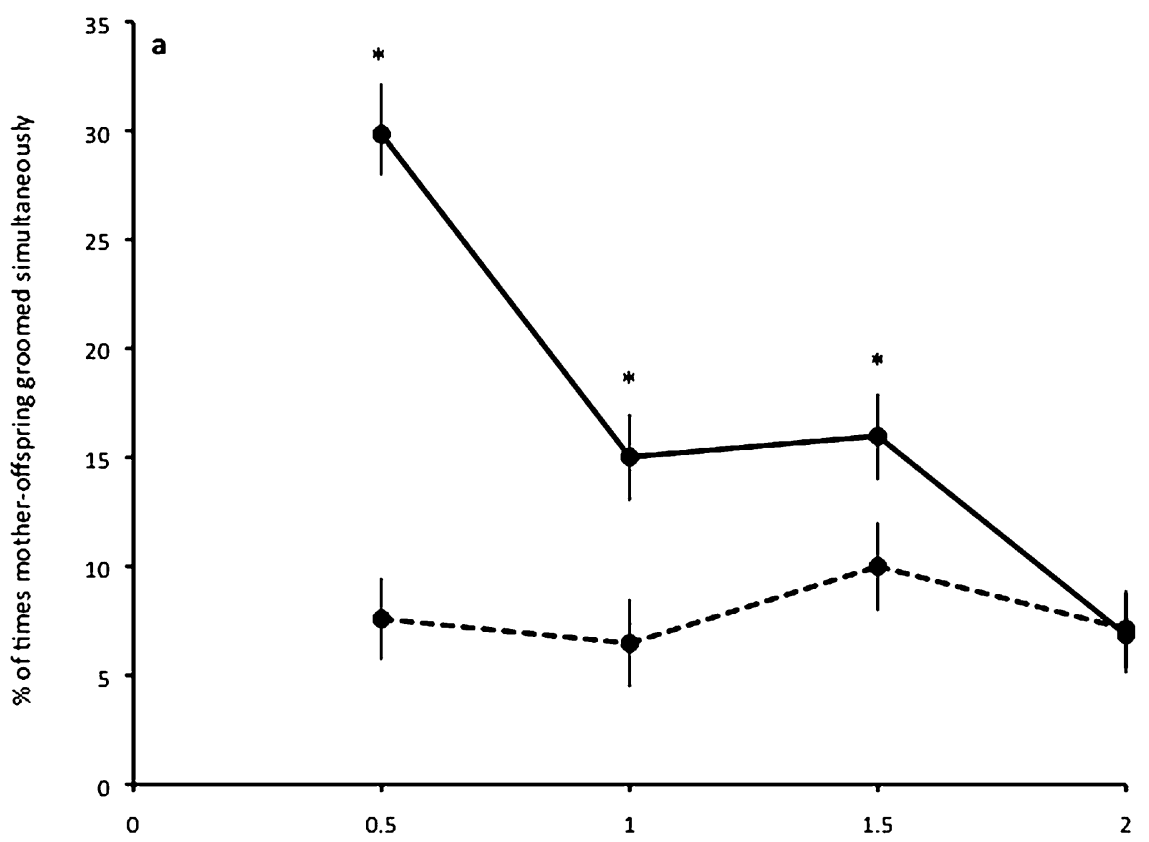

(a)

Figure 1. Mean ( \pm SEM) percentage of instances daughters (-) and sons (- - -) groomed together with (a) mothers and (b) control females at different ages. $* p<0.05$ vs. males (see text for statistical analyses).

one year old (Figure 1b). Up to 6 months of age, the simultaneous grooming percentages of daughters and mothers were significantly higher than these were with control females (means difference $=13.94, p<0.0001$, $1-\beta=0.85$ ). Sons, by contrast, scarcely ever groomed simultaneously with mothers or control females nor did they show any trends throughout time.

The percentage of time spent grooming simultaneously with an adult female (mother or control) varied significantly with age (GLMM: $N=1094$, $\left.F_{3,211.1}=5.224, p=0.001,1-\beta=0.95\right)$, with an interaction between adult female model $\times$ age $\left(F_{3,196.9}=4.145, p=0.007,1-\beta=0.91\right)$ and sex of infant $\times$ adult female model $\times$ age $\left(F_{3,196.9}=4.559, p=0.004\right.$, $1-\beta=0.83)$. Figure 2 summarises these complex results. Throughout their first 6 months of life, sons and daughters both spent the majority of time simultaneously grooming alongside their mothers. By one year, both daughters and sons significantly decreased the percentage of time simul- 


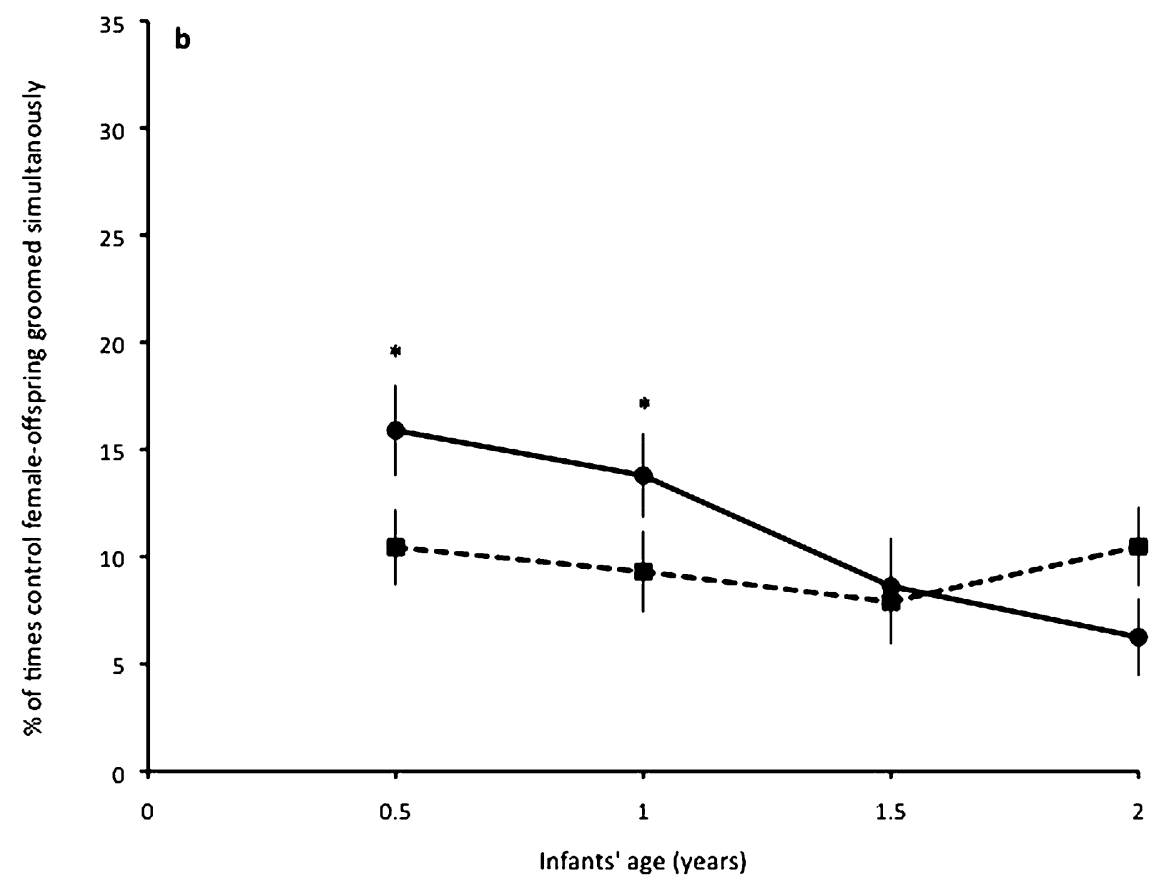

(b)

Figure 1. (Continued.)

taneously grooming (diff. $=-22.88, p<0.0001,1-\beta=0.94$ ). Behaviour of daughters remained constant until 2 years, while at 1.5 years of age, sons significantly increased time spent simultaneously grooming with mothers by comparison to daughters (Figure 2a), and relative to the previous (1.5 vs. 1 year of age: diff. $=22.71, p<0.0001,1-\beta=0.92$ ) and subsequent ages (1.5 vs. 2 years of age: diff. $=10.87, p<0.0001$, $1-\beta=0.84)$. During their first 6 months, daughters and sons spent significantly less time grooming alongside control females than they did alongside their mothers (diff. $=-19.94, p<0.0001,1-\beta=0.89$ ). Sons showed similar trends until 2 years old (Figure $2 b$ ). However, 1.5 years old daughters significantly increased time grooming together with control females when compared with mothers (diff. $=24.64, p<0.0001,1-\beta=1$ ), sons (diff. $=15.59, p<0.0001,1-\beta=0.84$ ), and the previous age (1.5 vs. 1 year of age: diff. $=26.58, p<0.0001,1-\beta=1$; Figure $2 b)$. 


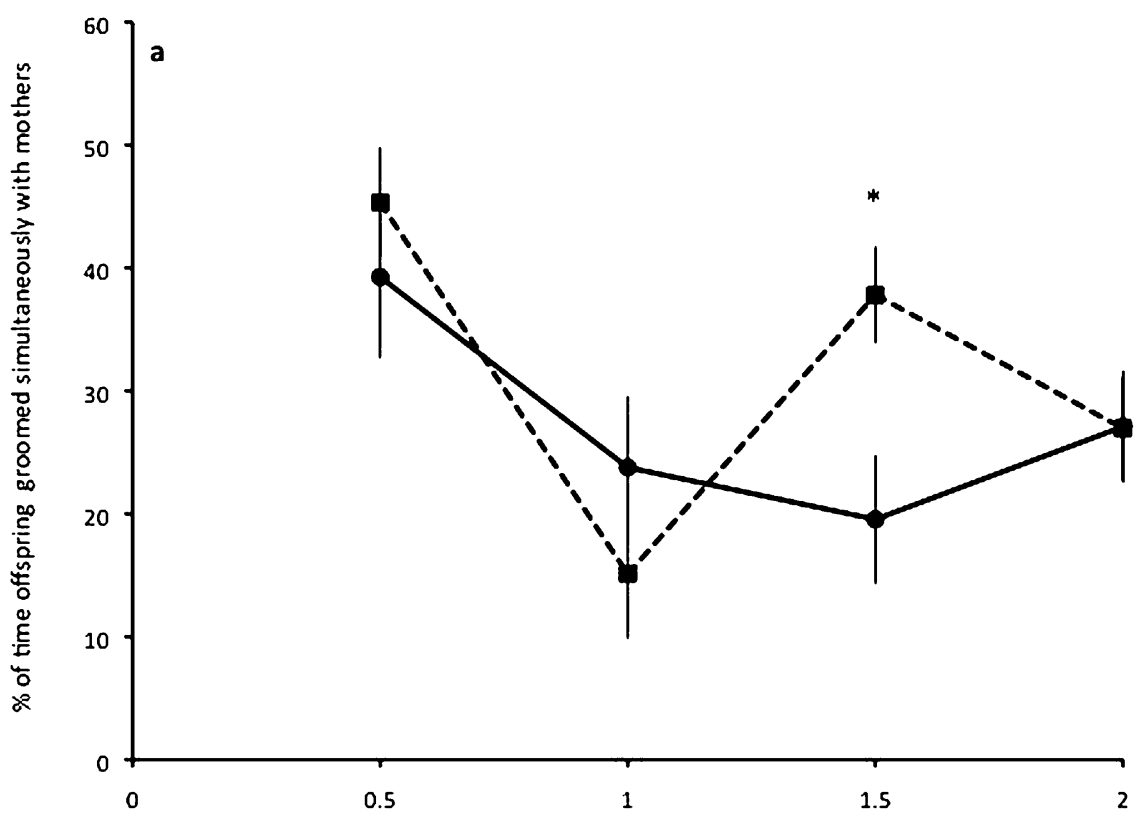

(a)

Figure 2. Mean ( \pm SEM) percentage of time daughters (-) and sons (- - -) lasted grooming jointly with (a) mothers and (b) control females. ${ }^{*} p<0.05$ vs. males (see text for statistical analyses).

\section{Grooming agreement}

We found no significant agreement in grooming frequency between immatures of either sex and a control female model. By contrast, daughters' grooming duration was significantly concordant with the grooming durations of their mothers throughout their first six months of life $(a \pm \mathrm{SE}=$ $0.46 \pm 0.38, b=0.51 \pm 0.22, N=39, R^{2}=0.4, t_{11}=2.26, p=0.045$, $1-\beta=0.67$; Figure $3 \mathrm{a}$ ), and continued to be so up to one year of age only $\left(a=0.48 \pm 0.41, b=0.44 \pm 0.19, N=60, R^{2}=0.38, t_{14}=2.15\right.$, $p=0.05,1-\beta=0.77$; Figure $3 b$ ). Immature male grooming duration was dissimilar for both mothers and control female models at all ages.

Kin bias, rank bias and idiosyncratic preferences matching

Tables 2-4 summarise results for kin bias, rank bias and idiosyncratic preferences. Daughters at 1.5 years significantly replicated individual maternal kin biases (within-subjects effects: Wald $\chi^{2}=7.322$, df $=1, p=0.007$ ) and 


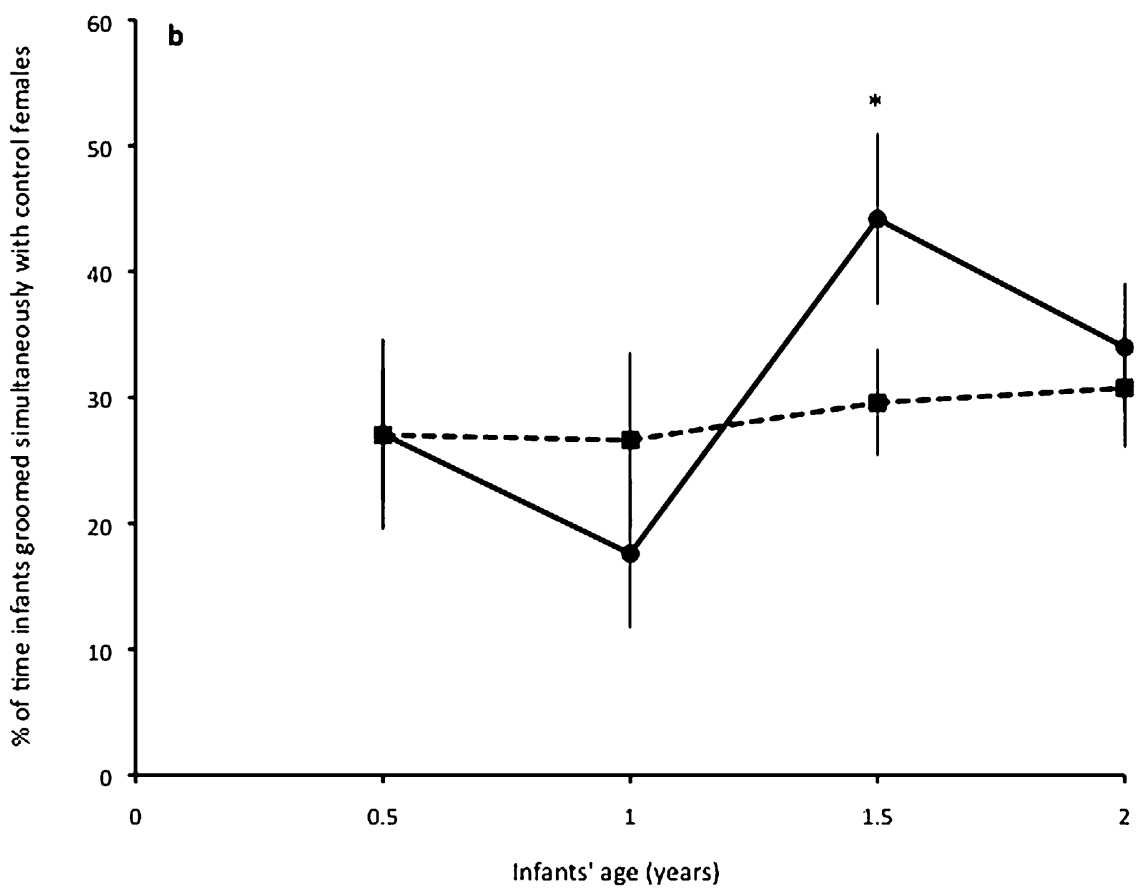

(b)

Figure 2. (Continued.)

followed the overall tendency of mothers to allocate more grooming to kin (between-subjects: Wald $\chi^{2}=9.393, \mathrm{df}=1, p=0.002$; Table 2). However, within- and between-subjects slopes were significantly different (Wald $\chi^{2}=10.53, \mathrm{df}=1, p=0.001$ ). This last effect is illustrated in Figure 4a where in all 14 cases, the within-subjects slopes match individual maternal kin biases. Ten daughters' within-subjects slopes followed the betweensubjects tendency to allocate more grooming time to kin, but there was much variation in the slopes. On the other hand, the within-subjects slopes of 4 daughters showed the opposite trend of allocating more grooming to nonkin. Males at 6 months showed a significant trend to allocate grooming in a similar fashion to control females (between-subjects: Wald $\chi^{2}=5.166$, df $=1, p=0.023$; Table 2). Nonetheless, they did not match individual females' kin preferences, within-subjects effects being non-significant.

Neither daughters nor sons matched maternal rank biases at any age (Table 3), nor were there immature female rank biases following control models. However, yearling males significantly followed within- (Wald $\chi^{2}=12.725$, 


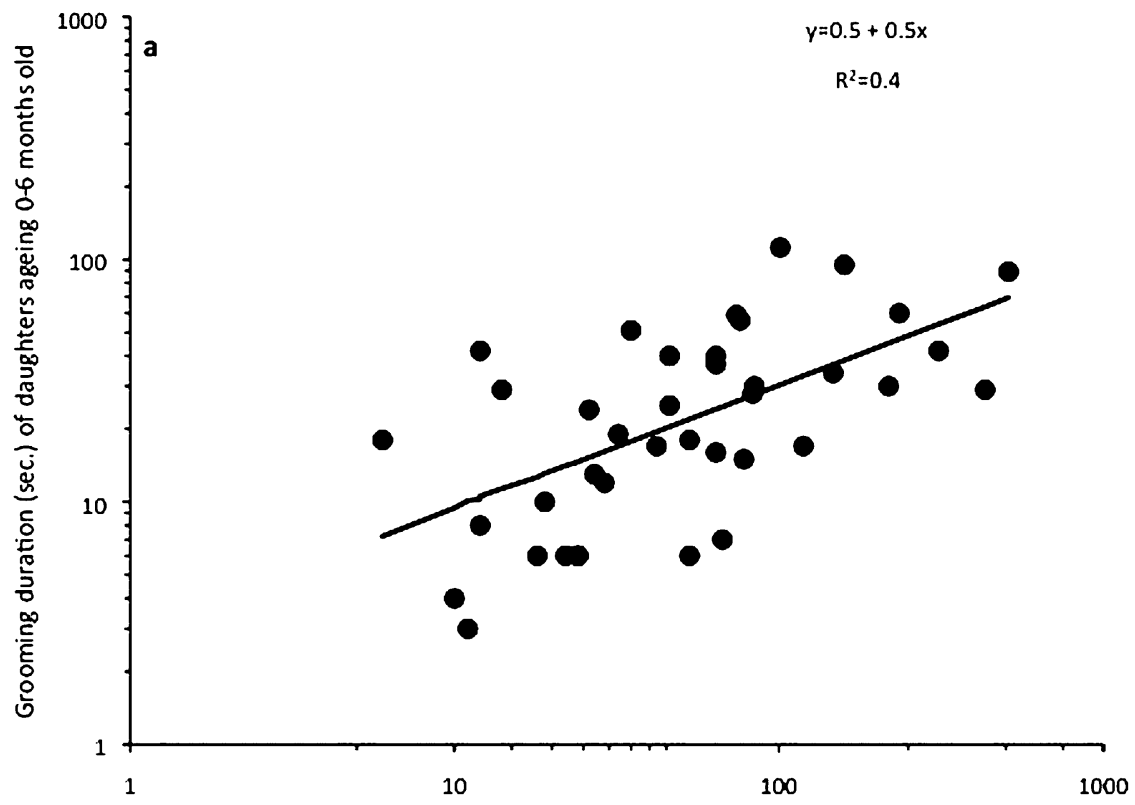

(a)

Figure 3. Duration concordance between the grooming bouts of mothers and (a) 6 months old and (b) 1 year old daughters. Each datapoint accounts for the same animal groomed first by the mother and subsequently and independently by her daughter (see Figure 1). Data are shown in a $\log _{10}-\log _{10}$ scale, as these were the data used in analyses (see Methods).

$\mathrm{df}=1, p<0.001)$ and between-control females rank bias preferences (Wald $\chi^{2}=13.422, \mathrm{df}=1, p<0.001$ ). In both cases, males showed a tendency to preferentially groom high-ranking animals. Within- and betweensubjects slopes were significantly different (Wald $\chi^{2}=5.256$, df $=1$, $p=0.022)$. Between-slope difference was mainly due to variation in individual slopes $(N=10)$, but also to 2 infant males allocating more grooming to subordinate animals (Figure $4 \mathrm{~b}$ ). In all cases, male immature slopes matched those of control females.

At 6 months of age, daughters' idiosyncratic preferences slopes followed those of mothers (within-subjects: Wald $\chi^{2}=6.119$, $\mathrm{df}=1, p=0.013$; Table 4). They also significantly matched the overall maternal trend to allocate more grooming to preferred partners (between-subjects: Wald $\chi^{2}=9.219$, $\mathrm{df}=1, p=0.002)$. Within- and between-subjects slopes were significantly different (Wald $\chi^{2}=3.71$, $\mathrm{df}=1, p=0.05$ ). In addition to individual differences in slope for 11 daughters, 3 daughters showed trends opposite 


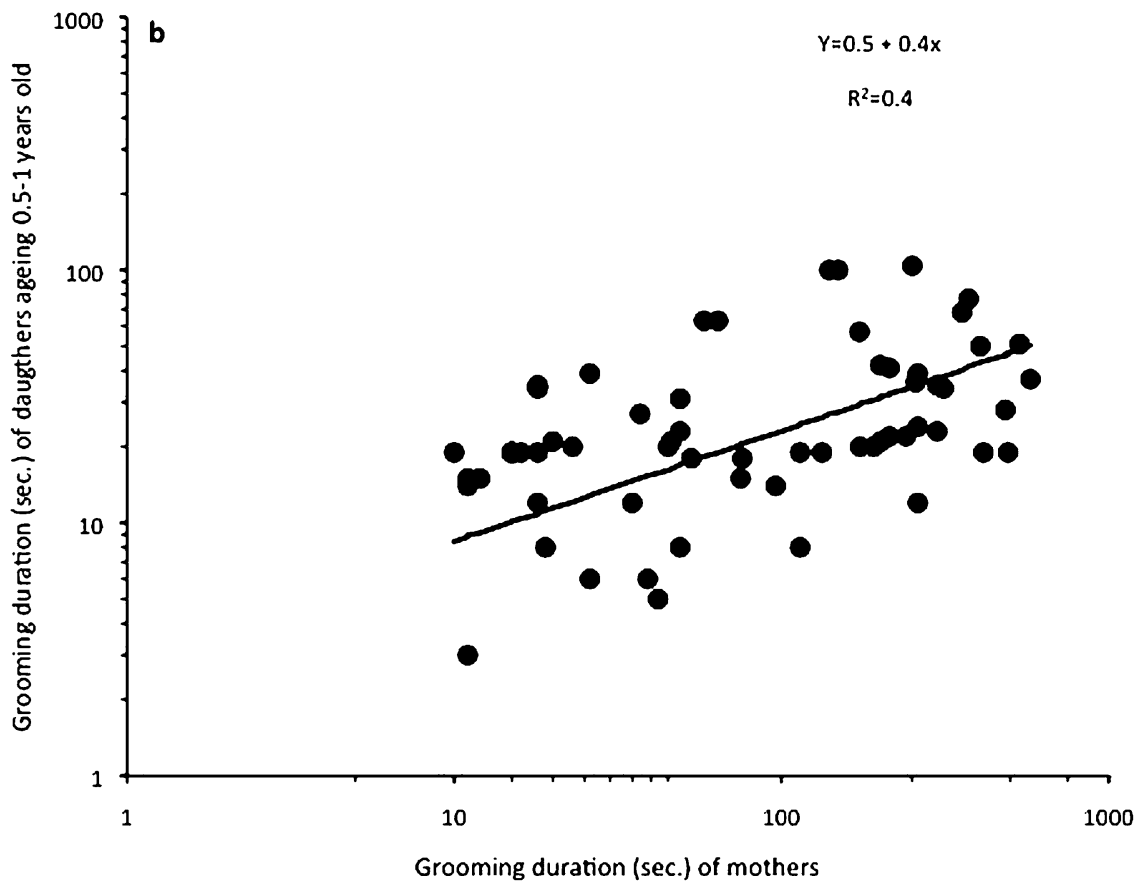

(b)

Figure 3. (Continued.)

to their mothers, allocating more grooming to their mothers' less preferred partners (Figure 4c). Sons showed no evidence of matching their mothers' idiosyncratic preferences, although they did followed the general maternal pattern of allocating more grooming to preferred partners at 0.5 (betweensubjects: Wald $\chi^{2}=11.787, \mathrm{df}=1, p=0.001$ ), 1 (Wald $\chi^{2}=11.87$, $\mathrm{df}=1, p<0.001$ ) and 2 years of age (Wald $\chi^{2}=11.87$, $\mathrm{df}=1$, $p<0.001)$. Moreover, male infants also accounted for significant betweensubjects effects concerning control females idiosyncratic preferences at 0.5 (Wald $\chi^{2}=4.657, \mathrm{df}=1, p<0.031$ ), 1.5 (Wald $\chi^{2}=18.827, \mathrm{df}=1$, $p<0.001$ ) and 2 years (Wald $\chi^{2}=7.945$, df $=1, p=0.005$; Table 4).

\section{Discussion}

Our results show that from early infancy, female and male stumptailed macaques follow different development pathways in learning how to allocate 
Table 2. Coefficients ( \pm SE) from within-subject centred Generalized Linear Mixed Model regressions between mothers and control females kin bias residuals and infants kin bias residuals.

\begin{tabular}{|c|c|c|c|c|}
\hline \multirow[t]{2}{*}{ Effect } & \multicolumn{2}{|c|}{ Mothers } & \multicolumn{2}{|c|}{ Control females } \\
\hline & Daughters & Sons & Daughters & Sons \\
\hline \multicolumn{5}{|l|}{ Up to 6 months old } \\
\hline Intercept & $-0.07 \pm 0.20$ & $-0.3 \pm 0.33$ & $-0.09 \pm 0.22$ & $-0.30 \pm 0.14$ \\
\hline Within-subjects & $0.27 \pm 0.79$ & $1.6 \pm 1.83$ & $0.24 \pm 0.69$ & $1.01 \pm 0.53$ \\
\hline Between-subjects & $0.46 \pm 0.79$ & $2.10 \pm 1.84$ & $0.33 \pm 0.71$ & $1.18 \pm 0.52 *$ \\
\hline $\begin{array}{l}\text { Within- vs } \\
\text { between-subjects }\end{array}$ & $0.19 \pm 0.16$ & $0.45 \pm 0.08 * *$ & $0.08 \pm 0.06$ & $0.17 \pm 0.09^{*}$ \\
\hline \multicolumn{5}{|l|}{ Up to 1 year old } \\
\hline Intercept & $-0.06 \pm 0.20$ & $0.28 \pm 0.43$ & $0.06 \pm 0.16$ & $-0.09 \pm 0.10$ \\
\hline Within-subjects & $0.05 \pm 0.82$ & $-1.52 \pm 2.31$ & $-0.30 \pm 0.52$ & $0.30 \pm 0.42$ \\
\hline Between-subjects & $0.21 \pm 0.83$ & $-1.45 \pm 2.34$ & $-0.23 \pm 0.53$ & $0.43 \pm 0.41$ \\
\hline $\begin{array}{l}\text { Within- vs } \\
\text { between-subjects }\end{array}$ & $0.15 \pm 0.08 *$ & $0.07 \pm 0.29$ & $0.07 \pm 0.04 *$ & $0.12 \pm 0.05^{* *}$ \\
\hline \multicolumn{5}{|l|}{ Up to 1.5 years old } \\
\hline Intercept & $-0.27 \pm 0.08 * *$ & $-0.37 \pm 0.40$ & $-0.15 \pm 0.18$ & $-0.13 \pm 0.10$ \\
\hline Within-subjects & $0.82 \pm 0.30 * *$ & $1.41 \pm 2.10$ & $0.33 \pm 0.59$ & $0.24 \pm 0.39$ \\
\hline Between-subjects & $0.96 \pm 0.31 * *$ & $2.01 \pm 2.20$ & $0.53 \pm 0.61$ & $0.49 \pm 0.39$ \\
\hline $\begin{array}{l}\text { Within- vs } \\
\text { between-subjects }\end{array}$ & $0.60 \pm 0.18^{* *}$ & $0.15 \pm 0.15$ & $0.19 \pm 0.04 * *$ & $0.25 \pm 0.07 * *$ \\
\hline \multicolumn{5}{|l|}{ Up to 2 years old } \\
\hline Intercept & $0.02 \pm 0.12$ & $0.31 \pm 0.35$ & $0.00 \pm 0.20$ & $-0.16 \pm 0.11$ \\
\hline Within-subjects & $-0.46 \pm 0.47$ & $-2.40 \pm 1.92$ & $-0.09 \pm 0.67$ & $0.39 \pm 0.38$ \\
\hline Between-subjects & $-0.11 \pm 0.53$ & $-1.68 \pm 1.93$ & $-0.01 \pm 0.68$ & $0.64 \pm 0.41$ \\
\hline $\begin{array}{l}\text { Within- vs } \\
\text { between-subjects }\end{array}$ & $0.35 \pm 0.23$ & $0.73 \pm 0.09 * *$ & $0.08 \pm 0.04^{*}$ & $0.25 \pm 0.07 * *$ \\
\hline
\end{tabular}

$*: p<0.05 ; * *: p<0.01$ based on Wald- $\chi^{2}$ test $(\mathrm{df}=1)$.

grooming. While mothers were the main source of information, this effect varied between the sexes, and mothers clearly were not the only source.

Our findings suggest that (1) females are more socially precocious than are males, (2) infant female and male stumptailed macaques choose different models for learning to allocate grooming, (3) females engage in more active learning activities than do males and (4) females learn to be kin-biased while males learn to be rank-biased. Care needs to be taken when interpreting the role of mothers' best friends as a model. In our work these females were chosen to act as a control for mothers' intrinsic (and assumed) importance 
Table 3. Coefficients ( \pm SE) from within-subject centred Generalized Linear Mixed Model regressions between mothers and control females rank bias residuals and infants rank bias residuals.

\begin{tabular}{|c|c|c|c|c|}
\hline \multirow[t]{2}{*}{ Effect } & \multicolumn{2}{|c|}{ Mothers } & \multicolumn{2}{|c|}{ Control females } \\
\hline & Daughters & Sons & Daughters & Sons \\
\hline \multicolumn{5}{|l|}{ Up to 6 months old } \\
\hline Intercept & $-0.01 \pm 0.14$ & $-0.08 \pm 0.05$ & $0.01 \pm 0.06$ & $-0.08 \pm 0.07$ \\
\hline Within-subjects & $-0.20 \pm 0.49$ & $0.10 \pm 0.30$ & $-0.05 \pm 0.18$ & $0.10 \pm 0.23$ \\
\hline Between-subjects & $0.27 \pm 0.50$ & $0.43 \pm 0.28$ & $0.01 \pm 0.18$ & $0.27 \pm 0.24$ \\
\hline $\begin{array}{l}\text { Within- vs } \\
\text { between-subjects }\end{array}$ & $0.48 \pm 0.19^{*}$ & $0.33 \pm 0.06^{* *}$ & $0.05 \pm 0.06$ & $0.17 \pm 0.06^{* *}$ \\
\hline \multicolumn{5}{|l|}{ Up to 1 year old } \\
\hline Intercept & $0.09 \pm 0.18$ & $-0.06 \pm 0.04$ & $0.08 \pm 0.06$ & $0.15 \pm 0.03 * *$ \\
\hline Within-subjects & $-0.48 \pm 0.72$ & $0.04 \pm 0.17$ & $-0.28 \pm 0.17$ & $-0.68 \pm 0.19 * *$ \\
\hline Between-subjects & $-0.30 \pm 0.70$ & $0.31 \pm 0.25$ & $-0.27 \pm 0.17$ & $-0.51 \pm 0.14^{* *}$ \\
\hline $\begin{array}{l}\text { Within- vs } \\
\text { between-subjects }\end{array}$ & $0.18 \pm 0.12$ & $0.27 \pm 0.22$ & $0.01 \pm 0.03$ & $0.17 \pm 0.07 *$ \\
\hline \multicolumn{5}{|l|}{ Up to 1.5 years old } \\
\hline Intercept & $-0.14 \pm 0.09$ & $-0.09 \pm 0.05$ & $-0.03 \pm 0.08$ & $-0.07 \pm 0.05$ \\
\hline Within-subjects & $-0.04 \pm 0.31$ & $-0.04 \pm 0.26$ & $0.01 \pm 0.24$ & $0.11 \pm 0.22$ \\
\hline Between-subjects & $0.54 \pm 0.34$ & $0.44 \pm 0.29$ & $0.10 \pm 0.22$ & $0.21 \pm 0.20$ \\
\hline $\begin{array}{l}\text { Within- vs } \\
\text { between-subjects }\end{array}$ & $0.58 \pm 0.16^{* *}$ & $0.48 \pm 0.13^{* *}$ & $0.09 \pm 0.04 *$ & $0.10 \pm 0.09$ \\
\hline \multicolumn{5}{|l|}{ Up to 2 years old } \\
\hline Intercept & $-0.11 \pm 0.09$ & $-0.03 \pm 0.04$ & $-0.06 \pm 0.06$ & $-0.03 \pm 0.04$ \\
\hline Within-subjects & $0.14 \pm 0.32$ & $-0.23 \pm 0.25$ & $0.09 \pm 0.21$ & $-0.08 \pm 0.17$ \\
\hline Between-subjects & $0.44 \pm 0.38$ & $0.18 \pm 0.23$ & $0.16 \pm 0.18$ & $0.12 \pm 0.14$ \\
\hline $\begin{array}{l}\text { Within- vs } \\
\text { between-subjects }\end{array}$ & $0.30 \pm 0.17$ & $0.41 \pm 0.11$ & $0.07 \pm 0.04$ & $0.21 \pm 0.07 * *$ \\
\hline
\end{tabular}

$*: p<0.05 ; * *: p<0.01$ based on Wald- $\chi^{2}$ test $(\mathrm{df}=1)$.

as a role model, not as an alternative. Nonetheless, similar to van de Waal et al. (2010) findings in vervet monkeys and as is expected to occur in a female bonded matrifocal species such as the stumptailed macaque (Fooden, 1990), older females act as a source of social knowledge for infants.

Daughters choose mothers as their model, since for females, social power lies in maintaining intense within-matriline collaboration. Thus, daughters in early infancy (0.5-1 year old) frequently groomed simultaneously with their mothers, allocated grooming durations following maternal durations and displayed the same idiosyncratic partner preferences as did their mothers. Not 
Table 4. Coefficients ( \pm SE) from within-subject centred Generalized Linear Mixed Model regressions between mothers and control females idiosyncratic preferences and infants idiosyncratic preferences.

\begin{tabular}{|c|c|c|c|c|}
\hline \multirow[t]{2}{*}{ Effect } & \multicolumn{2}{|c|}{ Mothers } & \multicolumn{2}{|c|}{ Control females } \\
\hline & Daughters & Sons & Daughters & Sons \\
\hline \multicolumn{5}{|l|}{ Up to 6 months old } \\
\hline Intercept & $0.00 \pm 0.00$ & $0.00 \pm 0.00$ & $0.00 \pm 0.01$ & $0.01 \pm 0.10$ \\
\hline Within-subjects & $0.21 \pm 0.08^{*}$ & $0.17 \pm 0.08$ & $0.11 \pm 0.07$ & $0.14 \pm 0.10$ \\
\hline Between-subjects & $0.39 \pm 0.13 * *$ & $0.56 \pm 0.11 * *$ & $0.10 \pm 0.06$ & $0.26 \pm 0.12 *$ \\
\hline $\begin{array}{l}\text { Within- vs } \\
\text { between-subjects }\end{array}$ & $0.18 \pm 0.09 *$ & $0.40 \pm 0.07 * *$ & $-0.01 \pm 0.08$ & $0.13 \pm 0.15$ \\
\hline \multicolumn{5}{|l|}{ Up to 1 year old } \\
\hline Intercept & $0.00 \pm 0.01$ & $-0.01 \pm 0.01$ & $-0.10 \pm 0.01$ & $0.02 \pm 0.01$ \\
\hline Within-subjects & $0.04 \pm 0.10$ & $0.03 \pm 0.10$ & $0.01 \pm 0.03$ & $0.08 \pm 0.07$ \\
\hline Between-subjects & $0.13 \pm 0.12$ & $0.72 \pm 0.21 * *$ & $0.13 \pm 0.06^{*}$ & $0.20 \pm 0.10$ \\
\hline $\begin{array}{l}\text { Within- vs } \\
\text { between-subjects }\end{array}$ & $0.09 \pm 0.15$ & $0.70 \pm 0.21 * *$ & $0.12 \pm 0.08$ & $0.12 \pm 0.12$ \\
\hline \multicolumn{5}{|l|}{ Up to 1.5 years old } \\
\hline Intercept & $0.00 \pm 0.01$ & $0.00 \pm 0.00$ & $0.01 \pm 0.00$ & $-0.01 \pm 0.01$ \\
\hline Within-subjects & $-0.08 \pm 0.05$ & $0.04 \pm 0.05$ & $0.05 \pm 0.05$ & $0.04 \pm 0.05$ \\
\hline Between-subjects & $0.07 \pm 0.12$ & $0.70 \pm 0.42$ & $0.18 \pm 0.03 * *$ & $0.31 \pm 0.07 * *$ \\
\hline $\begin{array}{l}\text { Within- vs } \\
\text { between-subjects }\end{array}$ & $0.15 \pm 0.11$ & $-0.26 \pm 0.21$ & $0.13 \pm 0.06^{*}$ & $0.30 \pm 0.10^{* *}$ \\
\hline \multicolumn{5}{|l|}{ Up to 2 years old } \\
\hline Intercept & $0.00 \pm 0.00$ & $-0.01 \pm 0.00$ & $-0.01 \pm 0.01$ & $0.01 \pm 0.01$ \\
\hline Within-subjects & $0.14 \pm 0.07$ & $0.02 \pm 0.11$ & $0.09 \pm 0.06$ & $0.07 \pm 0.07$ \\
\hline Between-subjects & $0.15 \pm 0.07$ & $0.72 \pm 0.23^{* *}$ & $0.03 \pm 0.04$ & $0.22 \pm 0.08^{* *}$ \\
\hline $\begin{array}{l}\text { Within- vs } \\
\text { between-subjects }\end{array}$ & $0.01 \pm 0.01$ & $0.66 \pm 0.43$ & $-0.06 \pm 0.06$ & $0.16 \pm 0.10$ \\
\hline
\end{tabular}

$*: p<0.05 ; * *: p<0.01$ based on Wald- $\chi^{2}$ test $(\mathrm{df}=1)$.

only were they learning how to behave as adults, but they were also actively integrating as members of their matriline.

Males, on the other hand, who eventually leave their natal group, require alliances (preferentially with same-sexed peers) to contend with the hazards of adult life, such as acquiring and maintaining a high rank. Therefore, they require a more general knowledge of group social dynamics (e.g., rank-biased interactions) rather than simply their own matriline's particular social traditions or needs. Immature males showed significant betweensubjects idiosyncratic preference correlations with mothers throughout most 


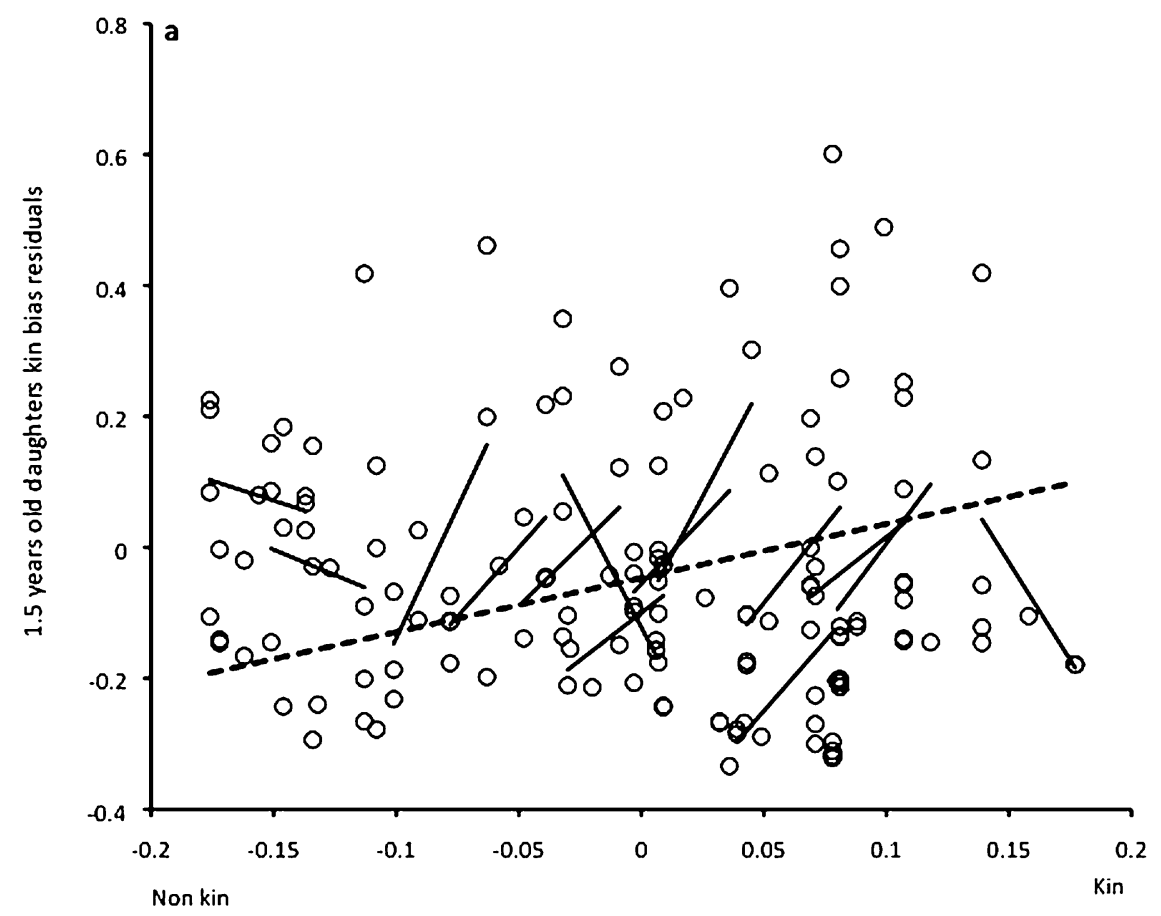

Within-subject centered maternal kin bias residuals

(a)

Figure 4. Plots of (a) 1.5 years old daughters' kin bias residuals against within-subject centred maternal kin bias residuals; (b) 1 year old sons' rank bias residuals against within-subject centred control females' rank bias residuals; (c) 6 months old daughters' idiosyncratic preferences against within-subject centred maternal idiosyncratic preferences. Each data point accounts for a same grooming recipient. Dashed lines show the between-subjects regression, and thin black lines the within-immature slopes. The slope trends are shown below the $x$-axis (a: non kin $\rightarrow$ kin gradient) and (b: dominants $\rightarrow$ subordinates gradient).

of their infancy without ever replicating these (except at 1.5 years when variability increased, although the regression coefficient remained the same). Six-month-old males showed also between-subjects agreement with control females' idiosyncratic preferences. At 1 year of age they showed the same rank bias preferences of control females, while never matching the overall maternal rank-biased grooming preferences. Given close proximity and bond with mothers, control females were chosen as models by males since they provide a knowledgeable and safe model (mothers' friends rarely behave agonistically to infants) from which to learn. However, males never 


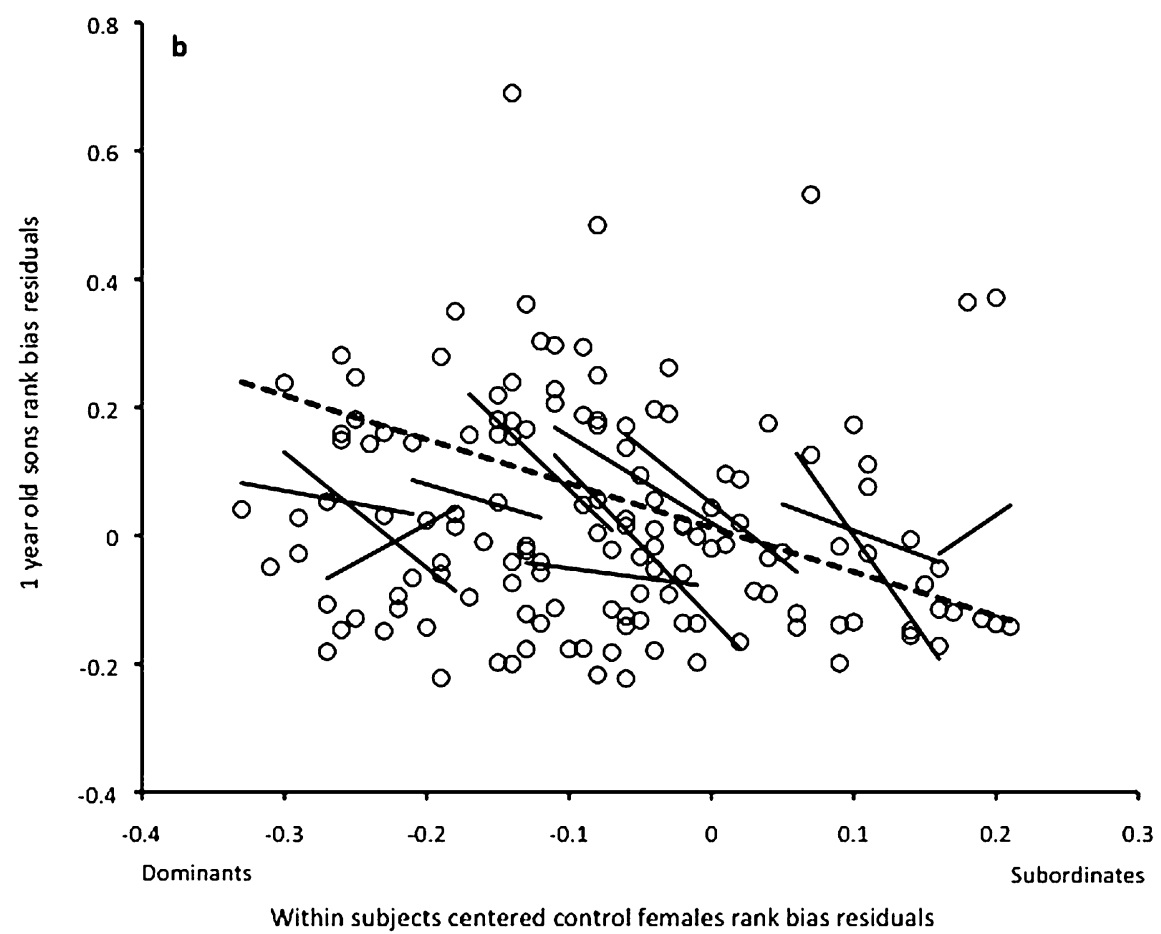

(b)

Figure 4. (Continued.)

mirrored control females' behaviour, and our results appear to relate only to observational learning. Observational learning does not require close proximity to the model (e.g., being within arm reach), but can be done from distance (e.g., van de Waal et al., 2010). Thus, resemblance to control females' behaviour does not eliminate the likely possibility that infant males learn to allocate grooming by watching other adult females, older peers, siblings and even adult males. As such, the significant correlations between 1-yearold males and control females rank-biased grooming preferences might not be exclusive, and similar biased correlations might be found by comparing other possible models.

The average inter-birth interval following a surviving infant is 1.7 years ( $\pm 0.3 \mathrm{SE}$ ) for stumptailed macaques, with weaning occurring 7-8 months earlier (Nieuwenhuijsen et al., 1985, and colony data). In our sample, by the time infants had reached 1.5 years of age, 25 mothers and 24 control females were either pregnant or had already given birth. Between 1 and 1.5 years 


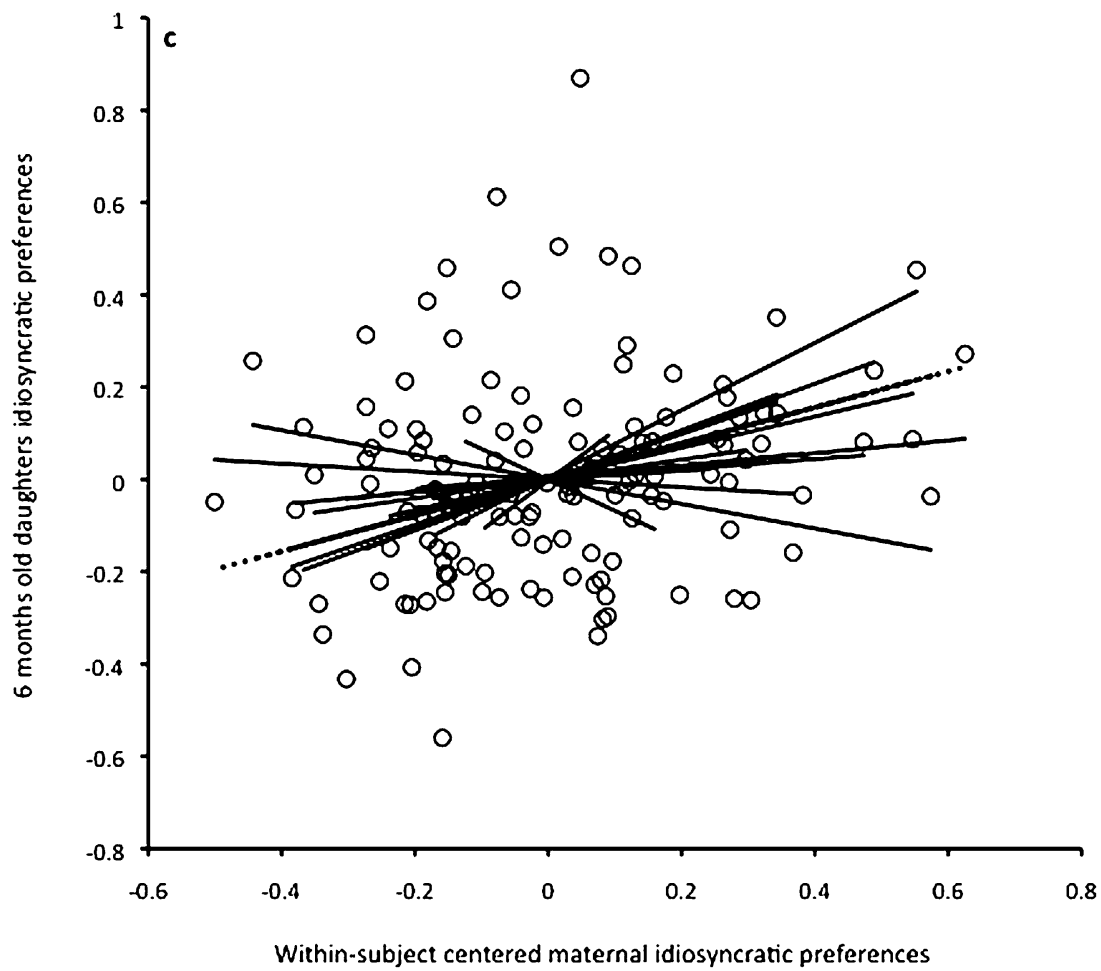

(c)

Figure 4. (Continued.)

of age, females increased their time grooming simultaneously with control females and matched maternal kin-biased preferences. Daughters intensified their bonds both with mothers and relatives, and also started mirroring control females behaviour, such as devoting more time grooming alongside them. By the same ages, sons increased time grooming simultaneously with mothers. These trends could be related to weaning, the advent of a new sibling, reduced maternal attention and greater social independence. We suggest that this infant early grooming behaviour relates to maintaining or strengthening social bonds rather than social learning.

Throughout the juvenile period, stumptailed macaques become independent of maternal care, and turn into the most active groomers of the group (particularly females) without reciprocation, and, as in other macaque species (e.g., Bernstein \& Ehardt, 1986), are main targets of aggression. Thus, juvenility is a time when immature female and male stumptailed 
macaques actively explore relationships distinct from those of their mothers. Females are socially precocious, and start exploring new relationships earlier than males; 1 and 1.5 years old female infants' idiosyncratic preferences showed significant correlations with between-control females' idiosyncratic preferences, as well as an increasing amount of time simultaneously grooming. Females were paying attention to and rehearsing on their own the control females' grooming choices, but were not copying these. By 2 years, the grooming preferences of immature females showed no correlation with either mothers or control females preferences, perhaps because they were already building new relationships. Male social development lags around 6 months by comparison to that of females, but that at all times they used maternal expertise as a secure platform to socialise.

Our results suggest a sex difference in the attention paid to the attributes of groomees. While infant females pay more attention to kinship, males attend to dominance-subordination relationships. Infant females are not precluded from developing rank-biased grooming preferences; daughters of dominant females tend to develop the same rank biased preferences as those of their mothers (in preparation). Nonetheless our results show that infants are psychologically prepared to attend and interpret social interactions in relation to their own sex-specific adult expectations.

Social learning in immature stumptailed macaques appears to correspond to the bonding and identification-based observational learning model (de Waal, 2001). Notwithstanding, daughters instead of behaving as passiveattentive apprentices did actively engage and were allowed to practice along with masters and on their own.

\section{Acknowledgements}

We are grateful to the two anonymous reviewers for their comments and suggestions to improve this paper. We also thank all students that helped collecting data for this study.

\section{References}

Agostini, I. \& Visalberghi, E. (2005). Social influences on the acquisition of sex-typical foraging patterns by juveniles in a group of wild tufted capuchin monkeys (Cebus nigritus). - Am. J. Primatol. 65: 335-351.

Altmann, J. (1974). Observational study of behaviour: sampling methods. — Behaviour 49: 227-267. 
Altmann, J. (1980). Baboon mothers and infants. — Cambridge University Press, Cambridge, MA.

Bachevalier, J. \& Hagger, C. (1991). Sex differences in the development of learning abilities in primates. - Psychoneuroendocrinology 16: 177-188.

Berman, C.M. (1982). The ontogeny of social relationships with group companions among free-ranging infant rhesus monkeys I. Social networks and differentiation. - Anim. Behav. 30: 149-162.

Berman, C.M. (1990). Intergenerational transmission of maternal rejection rates among freeranging rhesus monkeys. - Anim. Behav. 39: 329-337.

Berman, C.M. (2004). Developmental aspects of kin bias behaviour. - In: Kinship and behaviour in primates (Chapais, B. \& Berman, C.M., eds). Oxford University Press, Oxford, p. 317-346.

Berman, C.M. \& Kapsalis, E. (1999). Development of kin bias among rhesus monkeys: maternal transmission or individual learning? - Anim. Behav. 58: 883-894.

Berman, C.M., Rasmussen, K.L.R. \& Suomi, S.J. (1997). Group size, infant development and social networks in free-ranging rhesus monkeys. - Anim. Behav. 53: 405-421.

Bernstein, I.S. \& Ehardt, C. (1986). The influence of kinship and socialization on aggressive behaviour in rhesus monkeys (Macaca mulatta). — Anim. Behav. 34: 739-747.

Bernstein, I.S., Judge, P.G. \& Ruehlmann, T.E. (1993). Sex differences in adolescent rhesus monkey (Macaca mulatta) behaviour. - Am. J. Primatol. 31: 197-210.

Bowlby, J. (1969). Attachment and loss. Attachment. — Hogarth Press, London.

Bowlby, J. (1973). Attachment and loss. Separation: anxiety and anger. - Hogarth Press, London.

Boyd, R. \& Silk, J.B. (1983). A method for assigning cardinal dominance ranks. - Anim. Behav. 31: 45-48.

Broad, K.D., Curley, J.P. \& Keverne, E.B. (2006). Mother-infant bonding and the evolution of mammalian social relationships. — Phil. Trans. Roy. Soc. B 361: 2199-2214.

Cords, M. (2000). Grooming partners of immature blue monkeys (Cercopithecus mitis) in the Kakamega Forest, Kenya. — Int. J. Primatol. 21: 239-254.

Deputte, B.L. \& Quris, R. (1996). Socialization processes in primates: use of multivariate analyses. II - Influence of sex on social development of captive rhesus monkeys. Behav. Proc. 40: 85-96.

Drapier, M. \& Thierry, B. (2002). Social transmission of feeding techniques in Tonkean macaques? - Int. J. Primatol. 23: 105-122.

Dunbar, R.I.M. (1983). Structure of gelada baboon reproductive units. II. Social relationships between reproductive females. - Anim. Behav. 31: 556-564.

Ehardt, C.L. \& Bernstein, I.S. (1987). Patterns of affiliation among immature rhesus monkeys (Macaca mulatta). - Am. J. Primatol. 13: 255-269.

Fairbanks, L.A. (1989). Early experience and cross-generational continuity of mother-infant contact in vervet monkeys. - Dev. Psychol. 22: 669-681.

Fairbanks, L.A. \& McGuire, M.T. (1986). Age, reproductive value, and dominance-related behaviour in vervet monkey females: cross-generational influences on social relationships and reproduction. - Anim. Behav. 34: 1710-1721.

Faul, F., Erdfelder, E., Lang, A.-G. \& Buchner, A. (2007). G*Power 3: a flexible statistical power analysis program for the social, behavioural, and biomedical sciences. - Behav. Res. Methods 39: 175-191. 
Fooden, J. (1990). The bear macaque, Macaca arctoides, a systemic review. — J. Hum. Evol. 19: 607-686.

Galef Jr., B.G. (1996). Social influences on food preferences and feeding behaviour of vertebrates. - In: Why we eat what we eat: the psychology of eating (Capaldi, E.D., ed.). American Psychological Association, Washington, DC, p. 207-231.

Hagger, C. \& Bachevalier, J. (1991). Visual habit formation in 3-month-old monkeys (Macaca mulatta): reversal of sex difference following neonatal manipulation of androgens. - Behav. Brain Res. 45: 57-63.

Hiraiwa-Hasegawa, M. (1997). Development of sex differences in nonhuman primates. In: The evolving female: a life-history perspective (Morbeck, M.E., Galloway, A. \& Zihlman, A.L., eds). Princeton University Press, Princeton, NJ, p. 69-75.

Horvat, J.R. \& Kraemer, H.C. (1981). Infant socialization and maternal influence in chimpanzees. - Folia Primatol. 36: 99-110.

Huffman, M.A. (1996). Acquisition of innovative cultural behaviours in nonhuman primates: a case study of stone handling, a socially transmitted behaviour in Japanese macaques. - In: Social learning in animals: the roots of culture (Heyes, C.M. \& Galef Jr., B.G., eds). Academic Press, San Diego, CA, p. 267-289.

Joffe, T.H. (1997). Social pressures have selected for an extended juvenile period in primates. - J. Hum. Evol. 32: 593-605.

Keverne, E., Martel, F. \& Nevison, C. (1996). Primate brain evolution: genetic and functional considerations. — Proc. Roy. Soc. Lond. B: Biol. 263: 689-696.

Laland, K.N. (1996). Is social learning always locally adaptive? - Anim. Behav. 52: 637640.

Leca, J., Gunst, N. \& Huffman, M. (2007). Age-related differences in the performance, diffusion, and maintenance of stone handling, a behavioural tradition in Japanese macaques. — J. Hum. Evol. 53: 691-708.

Lee, P.C. \& Johnson, J.A. (1992). Sex differences in alliances, and the acquisition and maintenance of dominance status among immature primates. - In: Coalitions and alliances in humans and other animals (Harcourt, A.H. \& de Waal, F.B.M., eds). Oxford University Press, Oxford, p. 391-414.

Lonsdorf, E.V. (2005). Sex differences in the development of termite-fishing skills in the wild chimpanzees, Pan troglodytes schweinfurthii, of Gombe National Park, Tanzania. - Anim. Behav. 70: 673-683.

Lonsdorf, E.V. (2006). What is the role of mothers in the acquisition of termite-fishing behaviours in wild chimpanzees (Pan troglodytes schweinfurthii)? - Anim. Cogn. 9: 36-46.

Lonsdorf, E.V., Pusey, A.E. \& Eberly, L. (2004). Sex differences in learning in chimpanzees. - Nature 428: 715-716.

López-Vergara, L., Santillán-Doherty, A.M., Mayagoitia, L. \& Mondragón-Ceballos, R. (1989). Self and social grooming in stump-tailed macaques: effects of kin presence or absence within the group. - Behav. Proc. 18: 99-106.

Maestripieri, D. (2003). Similarities and affiliation and aggression between cross-fostered rhesus macaque females and their biological mothers. - Dev. Psychol. 43: 321-327.

Maestripieri, D., Lindell, S.G. \& Highley, J.D. (2007). Intergenerational transmission of maternal behaviour in rhesus macaques and its underlying mechanisms. — Dev. Psychobiol. 49: 165-171. 
Manson, J.H., Navarrete, C., Silk, J. \& Perry, S. (2004). Time-matched grooming in female primates? New analyses from two species. - Anim. Behav. 67: 493-500.

McCulloch, C. \& Searle, S. (2001). Generalized, linear and mixed models. - Wiley, New York, NY.

McGrew, W.C. (1992). Chimpanzee material culture: implications for human evolution. Cambridge University Press, Cambridge.

Mondragón-Ceballos, R. (2001). Interfering in affiliations: sabotaging by stumptailed macaques, Macaca arctoides. - Anim. Behav. 62: 1172-1187.

Morris, J., Jordan, C. \& Breedlove, S. (2004). Sexual differentiation of the vertebrate nervous system. - Nature Neurosci. 7: 1034-1039.

Nieuwenhuijsen, K., Lammers, A., De Neef, K. \& Slob, A. (1985). Reproduction and social rank in female stumptail Macaques (Macaca arctoides). — Int. J. Primatol. 6: 77-99.

Pereira, M.E. \& Altmann, J. (1985). Development of social behaviour in free-living nonhuman primates. - In: Nonhuman primate models for human growth and development (Watts, E.S., ed.). Alan R. Liss, New York, NY, p. 217-309.

Perry, S., Manson, J.H., Muniz, L., Gros-Louis, J. \& Vigilant, L. (2008). Kin-biased social behaviour in wild adult female white-faced capuchins, Cebus capucinus. - Anim. Behav. 76: 187-199.

van de Pol, M. \& Wright, J. (2009). A simple method for distinguishing within- versus between-subject effects mixed models. - Anim. Behav. 77: 753-758.

Rapoport, R.D. (1985). Like mother, like daughter: intergenerational transmission of DK response rates. - Publ. Opin. Q. 49: 198-208.

Sade, D. (1965). Some aspects of parent-offspring and sibling relations in a group of rhesus monkeys, with a discussion of grooming. - Am. J. Phys. Anthropol. 23: 1-17.

Schino, G. (2001). Grooming, competition and social rank among female primates: a metaanalysis. - Anim. Behav. 62: 265-271.

Schino, G., Aureli, F., Ventura, R. \& Troisi, A. (2004). A test of the cross-generational transmission of grooming preferences in macaques. - Ethology 100: 137-146.

Setchell, J.M. \& Lee, P.C. (2004). Development and sexual selection in primates. - In: Sexual selection in primates: new and comparative perspectives (Kappeler, P.M. \& van Schaik, C.P., eds). Cambridge University Press, Cambridge, MA, p. 175-195.

Suomi, S.J. (2005). Mother-infant attachment, peer relationships, and the development of social networks in rhesus monkeys. - Hum. Dev. 48: 67-79.

Tanaka, I. (1995). Matrilineal distribution of louse egg-handling techniques during grooming in free-ranging Japanese macaques. - Am. J. Phys. Anthropol. 98: 197-201.

Tanaka, I. (1998). Social diffusion of modified louse egg-handling techniques during grooming in free-ranging Japanese macaques. - Anim. Behav. 56: 1229-1236.

Venables, W.N., Smith, D.M. \& Team, R.D.C. (2007). An introduction to R. - Available online at http://www.r-project.org

de Waal, F.B.M. (1996). Macaque social culture: development and perpetuation of affiilative networks. - J. Comp. Psychol. 110: 147-154.

de Waal, F.B.M. (2001). The ape and the sushi master: cultural reflections of a primatologist. - Basic Books, New York, NY.

van de Waal, E., Reveney, N., Favre, C.M. \& Bshary, R. (2010). Selective attention to philopatric models causes directed social learning in wild vervet monkeys. - Proc. Roy. Soc. Lond. B: Biol.: in press (doi:10.1098/rspb.2009.2260). 
Wallen, K. (2005). Hormonal influences on sexually differentiated behaviour in nonhuman primates. - Front. Neurondocrinol. 26: 7-26.

Wallen, K., Goldfoot, D.A. \& Goy, R.W. (1981). Peer and maternal influences on the expression of foot-clasp mounting by juvenile male rhesus monkeys. - Dev. Psychobiol. 14: 299-309.

Walters, J.R. (1987). Transition to adulthood. — In: Primate societies (Smuts, B.B., Cheney, D.L., Seyfarth, R.M., Wrangham, R.W. \& Struhsaker, T.T., eds). University of Chicago Press, Chicago, IL, p. 358-369.

Weaver, A., Richardson, R., Worlein, J., de Waal, F.B.M. \& Laudenslager, M. (2004). Response to social challenge in young bonnet (Macaca radiata) and pigtail (Macaca nemestrina) macaques is related to early maternal experiences. - Am. J. Primatol. 62: 243-259.

Weaver, A. \& de Waal, F.B.M. (2003). The mother-offspring relationship as a template in social development: reconciliation in captive brown capuchins (Cebus apella). J. Comp. Psychol. 117: 101-110. 